\title{
O trans-humanismo como uma pós-religião e a mística em Tugendhat
}

\section{Transhumanism as a post-religion and mystic in Tugendhat}

\author{
Noli Bernardo Hahn* \\ Lucas Oliveira Vianna** \\ Matheus Thiago Carvalho Mendonça***
}

\begin{abstract}
Resumo: Neste artigo, tem-se como objetivo pensar o trans-humanismo nos limites da fronteira da religiáo, a caminho de uma pós-religiáo. Adota-se a revisão bibliográfica como metodologia principal, estruturando-se o estudo em quatro partes: (1) apresentaçáo da dessecularização da sociedade rumo à atitude mística intramundana na filosofia de Ernst Tugendhat como superação da morte; (2) análise das categorias religiosas e das promessas redentivas subjacentes ao projeto filosófico trans-humanista; (3) avaliação dos dilemas ético-sociais dele decorrentes, principalmente no capitalismo tardio e (4) um esboço de contribuição a partir do conceito de alteridade em Lévinas e Buber. Conclui-se que tal construto representa uma alternativa viável para se lidar tanto com os problemas que o trans-humanismo visa solucionar quanto com aqueles por ele ocasionados.
\end{abstract}

Palavras-chave: Trans-humanismo; ciência da religião; Tugendhat; mística; dessecularização.

Abstract: In this paper, it is aimed to think about transhumanism at the limits of the border of religion on the way to a post-religion. The literature review is adopted as the main methodology and the study is structured in four parts: (1) presentation of dessecularization of society towards the intramundane mystical attitude in Ernst Tugendhat's philosophy as an overcoming of death; (2) analysis of the underlying religious categories and redemptive promises of the trans-humanist philosophical project; (3) assessment of the resulting socioethical dilemmas, mainly in late stage capitalism; and (4) a contribution sketch based on the concept of alterity in Lévinas and Buber. The conclusion is that such theoretical framework poses a viable alternative to deal with the issues transhumanism aims to solve, as well as those that may arise from it.

Keywords: Transhumanism; study of religion; Tugendhat; mystic; desecularization.

\section{Introdução}

A tradição religiosa judaico-cristã, no momento inicial de sua narrativa cosmogônica, relata um dilema ético de primeira grandeza para a humanidade. Após o expresso estabelecimento de uma das primeiras limitaçóes impostas pela entidade divina à

\footnotetext{
* Doutor em Ciências da Religião (UMESP, São Bernardo do Campo-SP). Professor do PPG em Direito da URI (Santo Ângelo-RS).ORCID: 0000-0003-2637-5321 - contato: nolihahn@san.uri.br

** Mestrando em Direitos Humanos (UNIJUÍ, Ijuí-RS). ORCID: 0000-0002-3975-7188 - contato: lucasoliveiravianna@gmail.com

*** Bacharelando em Filosofia (UNLP, Argentina). ORCID: 0000-0002-1094-1213 - contato: thiago. matheus72010@gmail.com
} 
humanidade recém-criada, o polo metafísico antagonista argumenta: "Deus bem sabe que, no dia em que dele comerdes, vossos olhos se abrirão, e sereis como deuses, conhecedores do bem e do mal" (Livro de Gênesis, 3, 5, grifo nosso). Noutra ocorrência, a literatura poética pertencente ao cânon bíblico apresenta um texto controverso para os hermeneutas: "Sois deuses, sois todos filhos do Altíssimo" (Livro dos Salmos, 82, 6, grifo nosso).

Ora, o dilema acerca do tornar-se deuses sempre esteve em voga ao longo da história humana. O domínio humano sobre a natureza, a tecnocracia como ideologia (Benjamin, 1994; Habermas, 1997; Marcuse, 1991), o controle sobre a arquitetura do corpo humano e as constantes biotecnologias desenvolvidas ao longo dos últimos 50 anos tornam concebível a ideia de que o indivíduo humano é capaz de transcender o horizonte da temporalidade e tornar-se eterno. Acerca dessa faceta da experiência humana, a filosofia analítica de Ernst Tugendhat mostra-se profícua para pautar reflexóes teóricas acerca da morte como finitude e o impulso biológico de viver para sempre, mediado pelas potências e habilidades inerentes à sua condição.

Nesse contexto, o presente estudo lança a pergunta: em que consiste essencialmente o chamado trans-humanismo? Em que medida o projeto trans-humanista expressa-se como uma religião pós-moderna, autônoma e individualizada? Ou sua ênfase na autorrealização da pessoa humana pode ser designada como uma pós-religiâo, dado seu distanciamento das experiências religiosas mediadas pela comunidade e pela revelaçáo transcendental, arraigadas em confessionalidades históricas?

Para atender a esses questionamentos, este estudo mescla análise e interpretação, adotando a revisão bibliográfica como metodologia procedimental e empreendendo uma reflexão estruturada nos seguintes passos: apresentam-se, no primeiro momento, linhas gerais sobre a filosofia de Ernst Tugendhat com forte ênfase em seu conceito da mística intramundana como um meio de superação da morte como contingência; passa-se, a seguir, a uma análise das categorias religiosas e das promessas redentivas subjacentes ao projeto filosófico trans-humanista; na terceira parte, adota-se um tom crítico ao avaliar os dilemas éticos e sociais que podem exsurgir do projeto trans-humanista; como último tópico do desenvolvimento, esboça-se uma contribuição teórica para a discussão sobre o esforço humano em tornar-se transcendental e o conceito de alteridade em Buber e Lévinas como possível alternativa ao projeto tecnocrático trans-humanista.

\section{Dessecularização do mundo e mística em Tugendhat}

Considerado como um dos últimos filósofos analíticos, o alemão Ernst Tugendhat (1930-) constitui seu itinerário teórico na direção de compreender a humanidade em seus limites, com o propósito de desenvolver o ser humano autonomamente e ampliar as capacidades inerentes à sua condição. Murdoch (2013, p. 110) sintetiza o propósito do edifício teórico tugendhatiano como sendo o de elucubrar os sentidos, metas e razóes da experiência humana dentro de sua própria realidade. Assim, quaisquer hipóteses acerca do ser humano não devem partir de capacidades externas, mas sim ser investigadas dentro da constituição da própria pessoa. 
O ponto capital do trabalho de Tugendhat (2013, p. 14) é enxergar a linguagem proposicional como chave hermenêutica para a evoluçáo de muitos dos aspectos da humanidade, como moral, racionalidade e religião. Pode-se afirmar que a linguagem foi, inclusive, o que tornou possível a Tugendhat entender os mencionados fenômenos como resultantes da evolução biológica pela qual passou a humanidade. A dimensão biológica assoma-se em seus trabalhos mais recentes e se apresenta de maneira consoante com os propósitos tugendhatianos, quais sejam, os de situar os fenômenos da experiência humana em aspectos do mundo, de modo a serem explicáveis através da própria ontologia humana - isso é, sem o uso de categorias transcendentes (Brito, 2012; 2014).

Assim, neste contexto, o presente estudo, ao lançar-se sobre o fenômeno do trans-humanismo, deve instrumentalizar o edifício filosófico de Ernst Tugendhat como panorama teórico para entender a elaboração de uma mística que busca superar a morte como limite do horizonte da experiência humana.

\section{Morte como contingência e finitude e a relativização do "eu" em Tugendhat}

Efemeridade, finitude, impotência, pequenez. Todos esses elementos são provocados quando o indivíduo se depara com o tema da morte (Rohden, 2007, p. 367). "Quando uma pessoa se defronta seriamente com a possibilidade de sua morte, isto pode fazer com que ela se volte para si mesma e se libere de diversas preocupaçóes em que um costuma perder-se" (Tugendhat, 2002, p. 68), e isto ocorre porque o defrontamento com o fim da vida conduz a pessoa humana a deparar-se com a vida em si. Para o filósofo, "a morte é um caso notório da efemeridade e da indisponibilidade da vida humana”, que "atua não apenas como catalisador e intensificador da pergunta prática; ela também faz parte do conteúdo dessa pergunta” (Tugendhat, 2013, p. 115). Ora, o fato de que a morte seja uma condiçáo biológica inerente à arquitetura de todos os seres vivos - no entendimento do autor - não mitiga a dimensão trágica que ela possui, vez que a humanidade está ciente de seu fim.

Para Tugendhat (2013, p. 115), "o desejo de viver mais a todo custo tem uma justificação biológica”, porém tal impulso não altera o fato de que, no âmbito da experiência humana, a passagem para o que o filósofo chama de não ser ainda parece terrível e de que sua inevitabilidade demonstra a completa impotência humana. Nesse sentido, Tugendhat (2007) entende que, nos seres vivos passíveis da consciência do tempo, o desejo de permanecer vivo é natural, sob o risco de extinção. Assim, parece ser possível sustentar que o temor da morte é uma função biológica e não meramente uma assertiva metafísica. Esse medo da morte, próprio da experiência humana, e a vontade de seguir vivo a qualquer custo, possuem, em Tugendhat, um caráter funcional. Para ele, "o temor de cessar anda de máos dadas com a vontade de querer seguir vivendo, passo a passo. [...] Assim como o temor de morrer logo é funcional para a sobrevivência, o temor de ter que morrer algum dia seria náo funcional", dado sua consequência paralisante atuante na vontade de viver (Tugendhat, 2007, p. 165).

"A perspectiva da morte faz com que tenhamos uma consciência de ter apenas um tempo limitado, e de ter que estabelecer prioridades" (Tugendhat, 2007, p. 172, 


\section{6

tradução nossa). O autor entende que a percepção humana acerca da finitude do tempo e o imperativo de estabelecer prioridades abre a possibilidade para que a morte náo apenas afete a vivência humana, mas que também se transforme num objeto de uma relação com o indivíduo - como os demais afetos. Para Tugendhat (2007), considerando que, no curso da vida, o indivíduo pode relativizar seus afetos, hierarquizando-os, estabelecendo relaçóes de importância ou limitando-os - em que pese o fato de a morte figurar como o limite da vida, e, assim, uma aparente impossibilidade de relativizaçáo -, o autor entende ser possível que o temor da morte seja relativizado a partir da relativização (ou supressão) do $e u$ - o que, por sua vez, levaria a compreensão do fenômeno religioso e o surgimento da mística.

Diante de uma totalidade cósmica, que envolve o Universo e as demais pessoas, com notável grandeza e mistério, "o indivíduo sempre se vê como pequeno, impotente e ignorante. Nesse sentido, junto com os outros que dizem 'eu', o indivíduo se depara com uma grandeza [...] 'incomparável". Nessa ocasiáo, o indivíduo também "se vê diante de um poder incomparável e de um mistério que, confrontado com tudo o que ele aprendeu e esclareceu em detalhes, também é incomparável" (Tugendhat, 2013, p. 130).

Ante tal totalidade e mistério, o ser humano - em caso de não o relativizar - pode atribuir-lhe um caráter metafísico e transcendental. Acompanhando Rudolf Otto (2007), Tugendhat (2013, p. 131) descreve tal experiência como estar diante de uma categoria complexa que "compreende um elemento de qualidade absolutamente especial", um caráter do poder avassalador que "não é formulável em conceitos racionais; ela [a qualidade do poder avassalador] é 'inefável”" (Otto, 2007, p. 42). "O objeto realmente 'misterioso' é inapreensível não só porque minha apercepção do mesmo tem certas limitaçóes incontornáveis, mas porque me deparo com algo [...] cuja natureza e qualidade são incomensuráveis para minha natureza” (Otto, 2007, p. 59).

Nesse contexto, Rudolf Otto (2007) entende que o numinoso seria a essência da religiáo, que se estabelece em uma dimensão sentimental. Dado que, para Otto, os indivíduos se encontram vinculados à religião, Tugendhat, por sua vez, tenta explicar o fenômeno através da existência de afetos assimétricos e irregulares, que conduzem o ser humano a um estado ora de potência e suficiência, ora de impotência e necessidade.

Ora, nesse parâmetro filosófico - e aqui reside o ponto chave desta exposição -, o problema do mistério é solucionado de maneira distinta, inclusive oposta, pela religião e pela mística. Ambas têm a pretensão de solucionar o problema da contingência (Tugendhat, 2005). Assim, diante da tensão decorrente da inconstância própria da vida, a tentativa de compreender e integrar o numinoso ao cotidiano surge como possibilidade de aliviar os efeitos causados pelo mistério (Tugendhat, 2002, p. 110). Com isso, confrontado pelas angústias da experiência humana, o indivíduo se se dá com a religião e a mística como meio de compreensão.

\section{Atitude mística como superação da contingência}

Mística e religião compartilham a pretensão de resolver a questão da contingência, porém a interpretam de modos distintos (Tugendhat, 2007). Ao passo que a religiáo 
interpreta a contingência como produto da ação criativa de seres pessoais e metafísicos, dotados de intençóes e propósitos, a atitude mística pretende sobrelevar-se à contingência. É possível afirmar, ainda, que ambas residem no distanciamento de si mesmo, porém este movimento, na mística (ao menos como teorizada por Tugendhat), não recorre a nenhuma forma externa ao indivíduo. Assim, em síntese, a mística seria a atitude humana que "não remete a algo histórico [...] [ou] sobrenatural; é simplesmente uma atitude de se recolher em si, na qual a pessoa se torna consciente [...] da totalidade do mundo e assim chega à consciência de sua própria insignificância" (Tugendhat, 2006, p. 92).

Tugendhat (2013, p. 137) explica que "tanto na religião quanto na mística, recorre-se ao universo numinoso na elaboração das frustraçôes (efetivas ou a serem temidas) relativas aos desejos". No entanto, no âmbito da religião, tal recurso é utilizado com a projeçáo no universo de ferramentas que devem funcionar como auxílio. Por sua vez, na atitude mística, a tomada de consciência da existência do numinoso - que pode ser o universo, ser, Tao ou uma divindade - é instrumentalizado como referencial a partir do qual ele se distancia, de forma absoluta ou parcial, de seus afetos, com o objetivo de alcançar um suposto estado de paz de espírito.

No entanto, Tugendhat (2007) pergunta (i) em que dimensão o indivíduo humano é capaz de relacionar-se com algo superior, que náo possua traços animistas de personalização? (ii) Como é possível mensurar a despersonalização ocorrente na mística, desde a perspectiva das necessidades humanas? Em resposta a isso, Tugendhat entende que, no caso da consciência religiosa, a constante antropológica reside na necessidade de uma religião. Ao passo que, no tocante à atitude mística, o filósofo diz que é a própria mística - e não sua necessidade - que tem uma raiz antropológica, sem disto implicar que todos os seres humanos tiveram de se entender como místicos. A ideia é apenas que, "diferente da atitude religiosa, a atitude mística é uma possibilidade real fundada na essência humana, uma atitude que prescinde do recurso de uma revelação ou tradição" (Tugendhat, 2005, p. 14, traduçáo nossa). Como outrora mencionado, a tentativa de Tugendhat é a de erigir um fundamento que não seja subordinado à tradição ou revelação ou autoridade superior. Portanto, a ideia de mística não se vincula à concepção de uma moral náo autoritária, mas, sim, à de uma vida autônoma, pautada em preferências pessoais.

Em suma, como restou demonstrado, em resposta aos dilemas que permeiam a experiência humana Tugendhat fornece a atitude religiosa e a mística como ferramentas de mitigação. Dentre ambas, o autor apresenta a mística - que seria a superaçáo da religião - como o caminho mais adequado a uma vida estável, que pretende superar seus dilemas de forma autônoma. Isso porque a mística, diferente das religiôes confessionais, não estaria atrelada a confissóes ou éticas transcendentais, mas dependeria unicamente do indivíduo que a vivencia.

\section{Trans-humanismo como uma pós-religião}

A dessecularização pós-moderna da sociedade, com seu impulso metafísico, deu azo ao surgimento não apenas de correntes religiosas de cunho misticista, mas também de 
movimentos ideológicos que, em que pese não ostentar confessionalidade em sentido estrito, possuem subjacentes categorias e lógicas típicas de doutrinas religiosas, que se expressam mesmo em tradiçôes de jaez racionalista ou cientificista.

Como aponta Rieff (1966, pp. 7-8), o processo de desconversão das religiōes tradicionais é acompanhado de um processo de conversão a um sistema superior de símbolos, a ciência, que supriria o próximo predicado para a organização cultural da personalidade. É nesse contexto que surgem a tecnocracia e o cientificismo iluministas, panoramas sem os quais náo se pode compreender a ascensão do trans-humanismo.

Young (2009, p. 33.0) sintetiza o pensamento trans-humanista a partir de três categorias principais: a metafísica trans-humanista, que tem o mundo como um processo evolucionário de complexificação em direção a estruturas e operações cada vez mais complexas; uma psicologia trans-humanista, que enxerga o ser humano como um aspecto consciente da complexificação evolucionária que está imbuído do desejo de viver e evoluir; e uma ética trans-humanista, que defende o dever de promover essa vontade inata de evoluir, através da contínua busca pela expansão das habilidades humanas.

A aposição do prefixo "trans" (ou "pós") ao radical "humano" deve-se à crença de que as metamorfoses que serão operadas nas pessoas pela revolução biotecnológica modificarão seu patrimônio biológico e seu estatuto ontológico a tal ponto que náo mais se poderá denominar o ser resultante "humano" (Vilaça; Dias, 2014).

O pensamento trans-humanista expande-se em diversas vertentes, dentre as quais situa-se a tradição abolicionista - objeto deste estudo -, a qual objetiva, em síntese, a aboliçáo, por meio da biotecnologia, de toda forma de sofrimento, físico ou psicológico, náo apenas do ser humano, mas de todos os seres vivos (Harari, 2016; Pearce, 1995; 2007; Young, 2009). Isso seria obtido por avanços científicos no campo de drogas sintéticas neuromelhoradoras, interfaces neuromecânicas, implantes cerebrais, manipulação genética, dentre outros aprimoramentos biotecnocientíficos que culminariam, ao fim, na eliminação da própria morte (Young, 2009).

Não se tenciona, aqui, conduzir uma minuciosa descrição dos conceitos e categorias trans-humanistas, o que já foi feito com propriedade pelos autores das obras que compõem o referencial teórico, principalmente More (1990), Pearce (1995; 2007), Harari (2016), Kurzweil (2005), Steinhart (2014), Young (2009), Bostrom e Savulesco (2009), Vilaça e Dias (2014) e Vilaça e Palma (2012), mas, antes, recortar as similaridades da filosofia trans-humanista com as concepçóes religiosas, bem como o propósito, implícito ou explícito, de substituir tais cosmovisôes como estrutura de sentido na compreensão do mundo e localização [locus] do sujeito.

É importante destacar que muitos de seus proponentes preconizam-no expressamente como um substituto para as filosofias religiosas pré-Modernas. Nesse norte, Simon Young (2009, p. 23.0, traduçáo nossa), inicia sua obra "Designer Evolution: a transumanist manifesto" (em tradução livre, "Evolução Desenhada: um manifesto trans-humanista") justificando seu interesse por tal corrente em sua própria necessidade de uma teoria que providenciasse um mapa de sentido para a vida: "Pessoalmente, eu náo posso viver sem uma filosofia - um significado abrangente para a vida. Eu denomino a minha filosofia de trans-humanismo. Eu a defino como ‘a crença na superaçáo das limitaçóes humanas através da razão, da ciência e da tecnologia”". Kurzweil (2005) 
também aponta que os pontos de que o trans-humanismo trata, tais como o propósito das nossas vidas e a natureza da mortalidade e da imortalidade, são questóes que as religióes tradicionais sempre buscaram abordar.

A superação da morte é, talvez, o mais emblemático ideal compartilhado por religióes e trans-humanismo. Em verdade, a procura pela imortalidade é tão antiga quanto os registros históricos: o épico de Gilgamesh, datado em aproximadamente 1700 AEC, registra a jornada de um rei em sua busca pela imortalidade; posteriormente, exploradores empreenderam expediçôes em busca da fonte da juventude e alquimistas trabalharam arduamente para tentar obter o elixir da vida; e várias tradiçóes de taoísmo esotérico na China perseguiram a imortalidade através do controle ou da harmonia com as forças da natureza (More; Vita-More, 2013). A Torá judaica também está repleta de referências à superação da morte e não se pode ignorar a afirmação de São Paulo, em sua primeira carta aos coríntios, de que "o último inimigo a ser derrotado é a morte" (Primeira Epístola de São Paulo aos Coríntios, 15, 26).

De modo consonante, virtualmente todos os abolicionistas preveem que os avanços científicos conduzirão à imortalidade (Kurzweil, 2005; Steinhart, 2014). Young (2009, p. 81.0), por exemplo, afirma que, uma vez que nós já identificamos a receita genética da vida, é uma questão de tempo para descobrirmos o programa genético da morte. More (1990) vai além e defende que o pensamento trans-humanista é o único que contém os elementos necessários para preencher o vazio deixado pelas visóes religiosas de mundo, justamente por ser a única filosofia capaz de oferecer ao sujeito, por meio da ciência, a transcendência em relação ao horizonte último de sua existência, a morte.

Há, nesse sentido, um claro viés redentivo no pensamento trans-humanista, uma promessa de superação e libertação em relação a um mal alçado à condição de supremo - neste caso, as limitaçóes fisiológicas e o sofrimento que delas decorre (Kurzweil, 2005). Há a perspectiva, especialmente na tradição abolicionista, de que os avanços biotecnológicos eliminarão todas as atuais causas de sofrimento: doenças, miséria, morte (Steinhart, 2014) e até sentimentos indesejados, como o tédio (Pearce, 2007). Defende Young (2009, p. 60.0) que, assim como o humanismo nos libertou das cadeias da superstição, o trans-humanismo nos libertará de todas as nossas cadeias biológicas.

Essa projeçáo de imortalidade inclui não apenas a continuidade da existência, mas também a transformação do que o ser humano é em algo superior (Vilaça; Dias, 2014), uma ideia que também encontra correspondência nas religióes, seja na reencarnação aperfeiçoadora hindu, na ascensão a planos mais elevados no esoterismo ou na glorificação dos corpos judaico-cristã. Quanto a esta última, há ainda uma maior similaridade visto que, como lembra Hammes (2018), enquanto a maioria das religióes prevê um aperfeiçoamento do espírito posterior ao despojamento do corpo, em uma ótica dualista, o cristianismo histórico afirma expressamente uma ressurreição e uma glorificação da "carne". De qualquer modo, o desejo de tornar-se algo que transcenda e supere as limitaçóes da existência terrena é um tema religioso recorrente.

More (1990, p. 10) afirma que o objetivo trans-humanista é a continuação do processo de aprimoramento do ser humano em formas mais elevadas, complexas e poderosas, e que é esta expansão transcendente que confere significado à pessoa. Não se trata aqui, pois, do desejo de mera existência perpétua, mas de uma modificação de 
natureza que permita a obtenção de atributos até então inalcançáveis porque supostamente possuídos apenas por Deus (Harari, 2016).

Esse não é um objetivo apenas implícito na filosofia trans-humanista. David Pearce (2007, p. 12), um dos principais expoentes do pensamento, afirma expressamente que "a ciência natural aspira a uma perspectiva a partir de nenhures, a perspectiva ideal de um observador divino" (onisciência), e que "a ciência e a tecnologia em breve nos darão poderes divinos sobre todo o mundo vivo (onipotência)".

Trata-se, aqui, da clássica busca do ser humano, presente em inúmeras mitologias, religiosas ou não, de alcançar o seu criador e responder afirmativamente ao questionamento "não sabeis que sois deuses?". Nesse sentido, "ao buscar a felicidade e a imortalidade, os humanos estão na verdade tentando promover-se à condição de deuses”, e isso "não só porque esses atributos são divinos, mas igualmente porque, para superar a velhice e o sofrimento, terão de adquirir primeiro um controle de caráter divino sobre o próprio substrato biológico" (Harari, 2016, p. 98.2).

O próprio conceito de suprema bem-aventurança, presente em uma série de tradições religiosas - como o nórdico valhala [salão dos mortos], o islâmico jannah [abreviação do árabe para “jardim”], a cosmologia planetária mórmon ou a visão beatífica cristã -, é instrumentalizado profeticamente na filosofia trans-humanista: "estados de felicidade divina, ordens de magnitude mais belas do que qualquer coisa que a mente contemporânea possa acessar permearão o próprio tecido da realidade nas geraçóes vindouras" e "mesmo as imaginaçóes mais viris podem apreender apenas o sentido mais superficial do esplendor arrebatador que nos espera" (Pearce, 1995, s.p., tradução nossa). Não se pode ignorar a semelhança de tal citação com discursos religiosos tradicionais, como o de que "Nem olhos viram, nem ouvidos ouviram, nem jamais penetrou em coração humano o que Deus tem preparado para aqueles que o amam" (Primeira Epístola de São Paulo aos Coríntios, 2, 9).

Naturalmente, uma pretensão de tal nível não se poderia sustentar sem referências escatológicas, as quais são abundantes nas obras trans-humanistas. Há projeções proféticas de que nos próximos mil anos, mais ou menos, os substratos biológicos do sofrimento serão erradicados completamente (Pearce, 1995). A própria evolução é inserida em uma narrativa teleológica maior: "nosso processo de expansão infinita em direção a formas superiores deveria e substituirá o ideário religioso", uma vez que, sendo seres "perseguindo e promovendo uma expansão transcendente, nós somos a vanguarda da evolução", e a humanidade como a conhecemos é um mero "estágio temporário no caminho evolucionário” (More, 1990, p. 11, tradução nossa).

Com efeito, poucas descriçóes religiosas do que o futuro reserva para a raça humana são tão vívidas e extravagantes quanto o cenário profetizado por Young:

Liberto da escravidão biológica, uma espécie imortalizada, o Homo cyberneticus [sic] dirigir-se-á às estrelas. A vida consciente espalhar-se-á gradualmente pela galáxia, uma rede neural diversificando-se a cada desdobramento - uma miríade de formas de vida estendendo-se através do espaço e do tempo, até que finalmente, no futuro inimaginavelmente distante, o universo inteiro torne-se vivo, despertado para a sua própria natureza - uma mente cósmica tornada consciente de si mesma como uma entidade viva - onisciente, onipotente, onipresente. (Young, 2009, p. 87.0, tradução nossa). 
O trans-humanismo pressupóe, por fim, a crença de que os desenvolvimentos tecnológicos no campo biocientífico conduzirão a um aprimoramento não apenas intelectual, cognitivo e funcional, mas também moral. Esse não é um ideal inédito, mas a retomada da noção moderna, radicada na revoluçáo iluminista, de que o progresso científico da humanidade seria inevitavelmente acompanhado de um avanço moral (Vilaça; Dias, 2014, p. 347). Nessa concepção, “o progresso não é um acidente, mas uma necessidade. Certamente o mal e a imoralidade devem desaparecer; certamente a humanidade deve se tornar perfeita” (Spencer, 1892, p. 32, tradução nossa).

\section{Os dilemas ético-sociais exsurgentes do trans-humanismo}

A crença racionalista na relação causal entre progresso científico e desenvolvimento moral é severamente infirmada após as duas Guerras Mundiais, principalmente depois de a humanidade observar estupefata as teorias darwinistas serem utilizadas para embasar a eugenia nazista. Como lembra Viktor Frankl (1989, p. 45), ele próprio um judeu sobrevivente do Holocausto, "não foram apenas alguns ministérios de Berlim que inventaram as câmaras de gás de Maidanek, Auschwitz, Treblinka”; pelo contrário, "elas foram preparadas nos escritórios e salas de aula de cientistas e filósofos niilistas, entre os quais se contavam e contam alguns pensadores anglo-saxônicos laureados com o Prêmio Nobel." O projeto nazista é emblemático da insuficiência dos critérios unicamente científicos para o desenvolvimento da ética.

Como questionado por Vilaça e Dias (2014, p. 349), embora o trans-humanismo pressuponha que "tudo está na biologia, de modo que alguns desafios de outras ordens [...] seriam solucionados biologicamente", é certamente plausível que "benefícios biológicos individuais (por exemplo, extensão da vida de alguns) possam gerar problemas coletivos graves (por exemplo, escassez de suprimentos)”.

Diversos autores, como Fukuyama (2002), Sandel (2013), Habermas (1997; 2004) e Kass (2003) têm expressado profunda suspeição em relação às promessas triunfalistas do trans-humanismo. Tais pensadores têm sido denominados de bioconservadores. Náo obstante, problematizar essas questóes é essencial, na medida em que não é suficiente aguardar as inovações para só então discutir os problemas delas emergentes; antes, pode se mostrar necessário direcionar o processo de inovação em nome da justiça, tanto para evitar a produção de inovaçóes injustas quanto para garantir que os fins da pesquisa científica sejam eles próprios justos (Buchanan, 2011).

Uma preocupação recorrente nesse sentido é a de que a modificação do estatuto especista do ser humano, com a alteração de sua própria condição ontológica, torne-lhe inaplicável o ideal de direitos humanos (Fukuyama, 2002; Kass, 2003), principalmente se adotada a noção substancialista destes direitos, em oposição a perspectivas utilitaristas (Vilaça; Palma, 2012). Na outra face da mesma moeda está o receio de que a superioridade de capacidades dos humanos aprimorados lhes confira um estatuto moral superior em relação aos demais, tornando apenas a eles aplicáveis os direitos humanos (Buchanan, 2011). Novamente, o caráter recente de episódios como o Holocausto nazista e o genocídio de Ruanda, bem como a ascensão 
mundial de movimentos nazistas e de extrema-direita, conferem plausibilidade a tais preocupaçóes.

Deve-se ponderar, ainda, as implicaçóes no contexto do sistema socioeconômico capitalista, pois, como aponta Habermas (1997, p. 73), há no capitalismo tardio uma junção íntima entre técnica e ciência, criando "uma perspectiva na qual a evoluçáo do sistema social parece estar determinada pela lógica do progresso técnico-científico".

Isso conduz a uma inevitável valoração distinta das características humanas. Vilaça e Palma (2012, p. 1026) ressaltam que, invariavelmente, "contígua aos juízos de fato, há a presença de juízos de valor a partir dos quais é escolhido o que deve constituir a natureza humana, distinguindo o que deve ser combatido ou promovido, o 'mal' e o "bem'", e exemplificam que doenças e deficiências que são "características naturais, logo, inerentes à condição biológica do humano", ainda assim, "são tidas como índices de precariedade e imperfeição, sendo consideradas males".

O problema é que essa mensuração seja feita segundo critérios funcionalistas submetidos à economia de mercado, implicando uma veridição mercadológica da ciência, como se visualiza na relação questionável entre pesquisas farmacológicas e grupos econômicos. Visto que a agenda das pesquisas farmacêuticas é determinada pela demanda de mercado e pela influência política de grupos atuantes nos países desenvolvidos em que essas companhias estão sediadas, é verossímil esperar que avanços médicos que poderiam salvar milhóes de vidas em países menos desenvolvidos, sem o mesmo poder de compra, nunca sejam produzidos (Buchanan, 2011, p. 246).

Há autores que entendem que, mesmo no presente, já se verifica uma lógica elitista e excludente na pesquisa trans-humanista, já que o capital arrecadado para seu financiamento representa "uma forma de concentração de bens nas mãos de poucas instituições e pessoas", e que os hipotéticos aprimoramentos humanos determinam "a morte real de famintos e migrantes e uma seleção indireta de indivíduos aptos ao prolongamento da vida ou à pretensão da imortalidade" (Hammes, 2018, p. 449).

Não por outra razão, o próprio papa Francisco, em sua mensagem ao Fórum Econômico Mundial de 2018, "apelou para o emprego adequado de tecnologias que estão associadas aos projetos trans- e pós-humanistas" (Hammes, 2018, p. 447), defendendo que estas "devem ser empregadas de modo que contribuam para o serviço da humanidade e para a proteção da nossa casa comum” (Francisco, 2018, s.p.).

Os riscos da economicização capitalista das melhorias trans-humanistas são emblematicamente expressos na teoria de Robert Nozick (1974, p. 315), que defende a formação de um "supermercado genético", no qual pais poderiam escolher, dentre uma miríade de características, aquelas que desejam para seus filhos. Considerando que a hierarquização de fenótipos segundo sua desejabilidade (demanda) conduziria a uma valoração financeira desigual dentre eles, seguir-se-ia que apenas as famílias com maior capacidade aquisitiva poderiam escolher os genes socialmente mais bem estimados, no que parece ser o ápice da biopolítica foucaultiana. Assim, as inovaçôes trans-humanistas apresentam um potencial inédito de dimensionar desigualdades interpessoais, uma vez que transportam esse desequilíbrio dos campos econômico e social para o próprio âmbito de constituição substantiva do sujeito, efetivamente transmutando seu estatuto ontológico e ressignificando, nesse processo, seu valor moral e social. 
Além disso, considerando que o trans-humanismo prevê um melhoramento também nas ordens intelectual e moral dos indivíduos (Bostrom; Savulesco, 2009), pode-se facilmente prever uma restrição à participação política de indivíduos não melhorados, os quais seriam considerados desprovidos das habilidades necessárias à gestáo pública. Em que pese Buchanan (2011) argumentar que essa problemática está ligada não diretamente ao trans-humanismo, mas ao antigo argumento platônico de que apenas os mais inteligentes devem governar - e que, portanto, o problema estaria numa concepção elitista que independe dos aprimoramentos pós-humanistas -, é forçoso reconhecer que a celeuma, se não criada pelo trans-humanismo, certamente seria por ele agravada $\mathrm{e}$ que, enquanto o caminho recente da humanidade tem sido no sentido de reconhecer o direito à participação política de todos, o surgimento de distinções tão profundas entre as pessoas certamente reacenderia discursos de jaez aristocrática.

Essa hierarquização fenotípica representa, ainda, um condicionamento da liberdade subjetiva, uma vez que "a liberdade pessoal é também a liberdade da outra pessoa e é mutuamente constitutiva", o que implica que "a manipulação genética - pode dizer-se também transumanizadora - potencialmente rompe a liberdade de outrem, na medida em que pode condicionar essa mesma liberdade no próprio sujeito ou nos demais sujeitos" (Hammes, 2018, p. 444). Logo, não basta um panorama filosófico libertário para solucionar esses dilemas, já que as estruturas biopolíticas do capitalismo tardio utilizam náo mais os mecanismos coercitivos expressos no antigo modelo punitivo, mas sim uma dinâmica de incentivos hierarquizados:
[...] no caso de aprimoramentos que prometem maior produtividade, a preocupação, ao menos em Estados com uma "cultura de direitos", pode ser não uma ação estatal coercitiva (esterilização compulsória ou seleção genética compulsória de embriōes humanos), mas sim o subsídio estatal e o encorajamento social a que o indivíduo submeta-se a aprimoramentos. Essa eugenia "mais suave", não coercitiva, sustentar- -se-ia em outras forças que encorajam o recurso aos melhoramentos. A combinaçáo de encorajamento estatal, marketing [sic] privado vigoroso e uma 'mentalidade de rebanho' da cultura popular podem resultar em uma situação em que os indivíduos possuem mais escolhas, mas de uma forma negativa. Por exemplo, mesmo que o Estado não force as pessoas a usarem tecnologias para produzir embriōes "melhores", muitas pessoas podem se sentir compelidas a fazê-lo, diante de subsídios governamentais e a pressão social de evitar-se uma prole "abaixo do padrăo" (Buchanan, 2011, p. 22).

Nesse sentido, a linha entre poder e dever é mais tênue do que pode parecer à primeira vista, e o próprio preconceito social contra os náo melhorados pode conduzir a um condicionamento da liberdade individual. Exemplificativamente, caso um indivíduo "não aplicasse as biotecnologias na constituição da sua descendência (liberdade reprodutiva), e caso esta desenvolvesse algum problema de saúde evitável, sua condenação moral seria quase que incontornável" (Vilaça; Palma, 2012, p. 1035). Como salienta Sandel (2013, pp. 118.8-120.0), considerando que "é papel dos pais promover o bem-estar dos filhos [...], tais melhoramentos não se tornam somente aceitáveis, mas obrigatórios", e "da mesma forma que o governo pode exigir que os pais mandem os filhos para a escola, pode exigir que eles utilizem tecnologias genéticas (desde que seguras) para aumentar o QI dos filhos." 


\section{O amor como promessa redentiva superior}

O trans-humanismo, em sua ênfase abolicionista - conforme demonstrado no item anterior - não é capaz de cumprir satisfatoriamente o escopo ao qual se propóe. Sua manifestação, na condição de uma pós-religião, que busca, em alguma medida, superar as antigas manifestaçóes religiosas históricas, de natureza confessional e comunitária agora, tenciona abolir o sofrimento a partir de um aperfeiçoamento biotecnológico do ser humano com o propósito de transcender o horizonte da temporalidade. Nesse contexto, o presente estudo retoma a ideia de mística em Tugendhat, examinando especificamente a noção da alteridade como um de seus elementos centrais. Nesse aspecto, o pensamento do autor dialoga com outros místicos situados na tradição dialógica, como Emmanuel Levinas e Martin Buber, que defendem a alteridade como o núcleo de sentido tanto da mística quanto do amor. A partir disso, desenvolve-se o conceito de amor como uma promessa redentiva superior, que parece ser apta a preencher as comunidades humanas e mitigar suas mazelas vivenciais.

O conceito de mística na filosofia de Ernst Tugendhat, em oposição à chamada atitude religiosa, empreende uma busca pela transformação da autocompreensão; o caminho trilhado pela atitude mística é o de diminuir a própria importância e integrar-se à totalidade do mundo. Ao teorizar a chamada mística intramundana, Tugendhat afirma que seu núcleo reside - como explicado anteriormente - na relativização do indivíduo em relação ao mundo, ou seja, na compreensão de sua ligeira importância frente ao mundo e especialmente frente aos demais indivíduos.

Nesse sentido, Tugendhat (2013, p. 162) escreve: "entre as autorrelativizaçóes parciais e aquela não apenas parcial da mística, existe uma passagem movediça. $\mathrm{O}$ caráter específico da autorrelativização mística é o fato de ela acontecer em relação ao universo, isto é, a todos". Em continuidade, ao pensar em uma mística satisfatória como a relativização e o distanciamento do eu, verifica-se como consequente a abertura para o outro, que traria a ideia de compaixão, de um abrir-se para o semelhante e contemplá-lo em sua totalidade.

Em sentido semelhante é o pensamento de Martin Buber, filósofo judeu austríaco situado nas tradiçóes mística e dialógica, que defende justamente o encontro intersubjetivo - o que o autor chama de Eu-Tu - como uma manifestaçáo do divino (Buber, 1979). A proposta de Buber é "construir uma ontologia da relaçáo para entender uma antropologia do encontro que leva a e, ao mesmo tempo, é sustentada por uma teofania" (Von Zuben, 2015, pp. 947-948). Há, para o autor, uma correlação direta entre o intersubjetivo e o místico, pois "as linhas de todas as relaçóes, se prolongadas, entrecruzam-se no Tu eterno. Cada Tu individualizado é uma perspectiva para ele. Por meio de cada Tu individualizado a palavra-princípio invoca o Tu eterno" (Buber, 1979, p. 86). Assim sendo, Deus "é a estrutura metafísica que fornece o sentido e suporta a relação horizontal e vertical” (Martins, 2010, p. 36).

A perspectiva buberiana é consideravelmente similar à de outro filósofo judeu, Emmanuel Levinas, também radicado na tradição dialógica, que se destacou por desenvolver "uma concepçáo particular de ética, compreendida como o permanente reconhecimento do outro, que nos antecede e faz com que sejamos alguém" (Coelho 
Júnior, 2008, p. 213). Para Lévinas (2010, p. 141), a dimensão intersubjetiva, radicalmente pressuposta, é o elemento prévio e fundante de qualquer discussão ética: "o rosto do próximo me significa uma responsabilidade irrecusável, precedendo todo consentimento livre, todo pacto, todo contrato". Para o filósofo, a própria dimensão ontológica possui existência e adquire sentido apenas diante da necessidade de justiça na ordem transontológica. É essa exigência de justiça que "introduz a medida e a sincronia na ordem diacrônica da experiência ética primitiva entre a subjetividade nascente e a alteridade" (Maldonado-Torres, 2007, p. 152). Nessa perspectiva, a filosofia primeira não seria a metafísica ou a ontologia, mas a ética (Bresolin, 2013, p. 166).

Para ambos os autores, no núcleo das noçôes de alteridade e transcendência está o amor. O pensamento de Lévinas concebe o amor como "o sentimento que possibilita a abertura ética entre os homens" (Gomes; Freire, 2016, p. 1277), porque o amor "pressupóe [...] a exterioridade total, transcendente do outro, do amado" (Lévinas, 1988, p. 234). Nesse sentido, o amor é uma manifestação radical da transcendência em relação a si mesmo, pois "há no amor uma dualidade insuperável entre os seres - o outro sempre escapa - ou seja, a alteridade persiste" (Gomes; Freire, 2016, p. 1277). Em relação ao eu, o amor carrega consigo uma dimensáo de imperatividade, pois representa uma relação com o outro que é inevitável, convertendo-se em uma força que impulsiona o agir ético (Lima, 2007).

Também Buber (apud Von Zuben, 2003, p. 45) aponta que "o homem que ama vê a coisa como única, ela mesma em seu ser. O homem que ama confirma, na coisa cujo ser ele realiza, o conteúdo misterioso do todo". O amor encarna, portanto, os aspectos de mistério e transcendência que o ser humano insitamente sente em relação ao divino, e que reverberam, no entendimento desses autores, na relação com o Outro ou Tu. Para Buber (1979, p. 16), o amor "náo está ligado ao Eu de tal modo que o Tu fosse considerado um conteúdo, um objeto: ele se realiza entre o Eu e o Tu", e "aquele que desconhece isso, e o desconhece na totalidade de seu ser, náo conhece o amor, mesmo que atribua ao amor os sentimentos que vivencia, experimenta, percebe, exprime. $\mathrm{O}$ amor é uma força cósmica”.

Iris Murdoch (2013, p. 125), autora que possui pontos em comum com o pensamento de Tugendhat, trilha caminho similar ao defender que o amor que traz a resposta certa "é um exercício de justiça e realismo, e de realmente olhar. A dificuldade é manter a atenção fixa na situação real e impedir que ela retorne sub-repticiamente ao $e u$ com consolos e autopiedade, ressentimento, fantasia e desespero". Para a autora, a moralidade está vinculada ao misticismo pela forma como o indivíduo pretende alcançar o bem, prescindindo de uma fé histórica dogmática confessional. "O fundo da moralidade é propriamente algum tipo de misticismo, se por isso se quer dizer uma fé não dogmática, por essência não formulada, na realidade do Bem, de vez em quando relacionada à experiência" (Murdoch, 2013, p. 102). Noutra oportunidade, a autora sustenta que seria possível dizer que a verdadeira moralidade é uma forma de misticismo, tendo como fonte "um amor austero" (Murdoch, 2013, p. 126).

De forma similar, no cenário brasileiro, ao pensar-se sobre uma conjunção entre a alteridade e a expressão confessional religiosa, pode-se mencionar o exemplo de Padrinho Juruá, que, a partir de uma enfática declaração do "Caboclo", comenta acerca do culto 
da umbanda em que "os Espíritos dos ancestrais africanos, ex-escravos, como também os indígenas brasileiros, abarcando a todas as almas afins que estivessem aptas a trabalharem em prol dos irmáos encarnados, de pluralidades diversas, sejam de caráter étnicos, religiosos e socioculturais", no qual a "Manifestação do Espírito para a Caridade", por meio de um direcionamento do amor fraterno, tornar-se-ia a característica deste culto (Juruá, 2013, p. 18).

Isso sustenta a demonstração de que, para esses autores, há um liame inevitável entre transcendência, alteridade, moralidade e amor. A experiência religiosa impulsiona o indivíduo para fora de si em direção ao divino, possibilitando a transcendência em relação ao eu. Esse movimento não é de natureza dissemelhante daquele que o move em direção ao próximo e às suas necessidades. Assim como Deus é o "Totalmente Outro", também a intersubjetividade amorosa "se dá, com efeito, em uma relação de assimetria entre o eu e o outro, onde este, não sendo artifício identitário, é exterioridade absoluta que surge em sua própria positividade, inaugurando a diferença e a separaçáo" (Gomes; Freire, 2016, p. 1277). Há, portanto, "um paralelismo entre a esfera humana e a esfera do encontro com o TU eterno" (Von Zuben, 1979, p. LXI)1.

Nesse contexto, questiona-se: em que medida o trans-humanismo como (pós)religiáo estimula a alteridade e o desenvolvimento da humanidade como um todo? Em meados dos anos 1940 , ao refletir sobre a questão, Lewis (2017, p. 55) pondera: em que sentido a humanidade é detentora de poderes crescentes sobre a natureza? Para o autor, "o homem [sic] é tanto o paciente, ou objeto, quanto o dono, já que ele é o alvo tanto de bombas, quanto da propaganda". Com efeito, "desse ponto de vista, o que chamamos de poder do Homem [sic] sobre a Natureza, revela-se como poder exercido por algumas pessoas sobre as outras, tendo a Natureza por seu instrumento" (Lewis, 2017, p. 56).

Com efeito, retoma-se a crítica apresentada no momento anterior deste trabalho, de que a evolução do domínio humano sobre a tecnologia não implicaria necessariamente o progresso da humanidade, mas, talvez, fosse o início de múltiplas formas de opressáo social (Vianna; Borges, 2021). Em tom semelhante, ao analisar a promessa de Harari (2016) do surgimento de um humano divino [Homo deus], Hammes apresenta a crítica de que tal projeto "colapsa diante da simples evidência de que se transformaria inevitavelmente numa luta de deuses, ou de Prometeuses" (Hammes, 2018, p. 444)

Nessa linha, Hammes (2018) entende que a proposta trans-humanista "é a compreensão de evolução como realidade linear de complexificação e aperfeiçoamento". No entanto, o autor pondera que "a evolução não é um processo linear do simples ao complexo e do imperfeito ao mais perfeito. É antes uma condição da vida que se afirma distintamente frente ao ambiente circundante ao qual se adapta ou não". Com efeito, "implicada está a discussão a respeito do finalismo do processo evolutivo, em geral não aceito nas Ciências da Vida". Dessa maneira, ao fazer eco a sua crítica, não parece ser possível "reconhecer cientificamente uma finalidade que permitiria reconhecer a

1 "Os dois tipos de relação dialógicas são diferentes num ponto. Se o TU pode se tornar um ISSO na esfera humana, o TU eterno, sendo a alteridade absoluta, não pode, em termos ontológicos, ser reduzido a um ISSO" (Von Zuben, 1979, p. LXI). 
passagem do simples ao complexo como uma lei interna da natureza, não há razão para entender as mudanças na relação ser humano e máquina como uma progressão evolutiva". Em síntese definitiva: "pode ser evolução, mas nem por isso é progresso. Poderia ser entendido simplesmente como transformação e que pode ser para pior e precário" (Hammes, 2018, p. 448).

\section{Conclusáo}

Como analisado na primeira parte deste estudo, a filosofia de Ernst Tugendhat mostra-se útil e teoricamente viável para compreender a humanidade em seus limites, bem como seu projeto de desenvolvê-la autonomamente e ampliar as capacidades inerentes à sua condição. Nessa direçáo, com o fito de esclarecer os sentidos, metas e razóes da experiência humana dentro de sua própria realidade, o filósofo prescinde de tradiçóes fundadas em entes metafísicos pessoais ou revelaçóes religiosas.

Como problema principal apresentado pelo autor, tem-se a morte como limitadora da experiência humana e condicionante de sua vida. Para Tugendhat, nos seres vivos aptos a experimentar a consciência do tempo, seu desejo de permanecer vivo é tido como natural, pelo que o temor da morte constitui uma funçáo biológica e não meramente uma assertiva metafísica. Frente a essa questão, Tugendhat teoriza acerca da atitude religiosa e da atitude mística. Se a primeira interpreta a contingência como resultado da açấo criativa de seres pessoais e metafísicos, dotados de intençóes e propósitos, a segunda pretende superar a morte como contingência. Assim, nesse movimento de egocentricidade, o ser humano encara a totalidade da vida e mistério a partir de seu recolhimento sobre si mesmo, que prescinde de categorias religiosas históricas e transcendentais.

Nesse contexto, destaca-se que o projeto trans-humanista pode ser sintetizado a partir de três categorias principais: uma metafísica trans-humanista, que interpretaria o mundo como um processo evolucionário de complexificação; uma psicologia trans-humanista, que apreende o ser humano como um aspecto consciente da complexificação evolucionária, logo imbuído do desejo de viver e evoluir, como outrora levantado por Tugendhat; e, ao fim, uma ética trans-humanista, que defende a promoção da vontade inata de evoluir, através da contínua busca pela expansão das capacidades inerentes à arquitetura humana.

Percebeu-se que o projeto trans-humanista dá como pressuposta a crença de que os avanços no campo biocientífico conduzem a um aprimoramento não apenas intelectual, cognitivo e funcional, mas também moral da humanidade. Ora, essa perspectiva não é inédita, mas nada mais é que o retorno à noção moderna, radicada na revolução iluminista, de que o progresso científico humano seria inexoravelmente seguido de um avanço moral. Como os construtores da torre de Babel da mitologia cosmogônica judaica do livro de Gênesis, os postulantes do projeto trans-humanista ignoram o fato de que o domínio humano sobre a natureza "pode ser evolução, mas nem por isso é progresso. Poderia ser [...] simplesmente [...] transformação e que pode ser para [algo] pior e precário" (Hammes, 2018, p. 448). 
Por fim, apresenta-se a noção de amor, não como conceito abstrato e amorfo, mas delimitado e estruturado filosoficamente pelas consideraçóes acima expostas, como um paradigma redentivo possível em contraposição à tecnocracia transumanista. Salienta-se, apenas, que se tem por objetivo no presente trabalho não oferecer um prognóstico para questóes que são radicalmente complexas, senáo que apresentar um diagnóstico dos axiomas subjacentes ao projeto transumanista, problematizar suas possíveis implicaçóes éticas e sociais e delinear as linhas gerais de um panorama alternativo para lidar com as celeumas que os aprimoramentos transumanos objetivam resolver.

\section{Referências}

BEALE, G. K.; CARSON, D. A. (Orgs.). Comentário do uso do Antigo Testamento no Novo Testamento. São Paulo: Vida Nova, 2014.

BEASLEY-MURRAY, G. R. John. 2nd ed. WBC 36. Waco: Word, 1999.

BENJAMIN, W. Teses sobre o conceito da história. In: BENJAMIN, W. Magia e técnica, arte e política. Obras Escolhidas I. São Paulo: Brasiliense, 1994.

BOSTROM, N.; SAVULESCU, J. (Eds). Human enhancement. Oxford: Oxford University Press, 2009.

BRESOLIN, K. Autonomia versus heteronomia: o princípio da moral em Kant e Levinas. Conjectura, Caxias do Sul, v. 18, n. 3, pp. 166-183, set./dez. 2013.

BRITO, A. N. A moral e os valores numa perspectiva naturalizada e evolucionista. In: BRITO, A. N.; REGNER, A. C. (Orgs.). Ecos de Darwin. Sáo Leopoldo: Unisinos, 2012. pp. 238-275.

BRITO, A. N. Naturalismo moral. In: TORRES, J. C. B. (org.). Manual de Ética: questóes de ética teórica e aplicada. Petrópolis: Vozes, 2014. pp. 342-364.

BUBER, M. Eu e Tu. São Paulo: Moraes, 1979.

BUCHANAN, A. Beyond humanity? The Ethics of Biomedical Enhancement. Oxford: Oxford University Press, 2011.

COELHO JUNIOR, N. Da fenomenologia à ética como filosofia primeira: notas sobre a noção de alteridade no pensamento de E. Lévinas. Estudos e Pesquisas em Psicologia, Rio de Janeiro, v. 8, n. 2, pp. 213-233, ago. 2008.

FRANCISCO, P. Mensagem do Papa Francisco ao Presidente Executivo do Fórum Econômico Mundial de Davos (Suíça). Disponível em: http://www.vatican.valcontent/francesco/pt/messages/pontmessages/2018/doauments/papa-francesco_20180112_messaggio-davos2018.html. Acesso em:20 nov. 2020.

FRANKL, V. Sede de Sentido. São Paulo, Quadrante, 1989.

FUKUYAMA, F. Our posthuman future: consequences of the biotechnology revolution. New York: Farrar, Straus and Giroux, 2002. 
GOMES, R.; FREIRE, J. C. O amor e as suas relaçóes com a alteridade, o desejo e a criação. Estudos e Pesquisas em Psicologia, Rio de Janeiro, v. 16, n. 4, pp. 1271 1287, dez. 2016.

HABERMAS, J. O futuro da natureza humana: a caminho de uma eugenia liberal? São Paulo: Martins Fontes, 2004.

HABERMAS, J. Técnica e ciência como ideologia. In: HABERMAS, J. (Org.). Técnica e ciência como “ideologia”. Lisboa: Ediçōes 70, 1997. pp. 45-92.

HAMMES, E. Transumanismo e Pós-humanismo: uma aproximação éticoteológica. Perspectiva Teológica, Belo Horizonte, v. 50, n. 3, pp. 431-452, 2018.

HARARI, Y. N. Homo Deus: uma breve história do amanhã. São Paulo: Cia das Letras, 2016.

JOHNSON JR., S. L. The Old Testament in the New: An Argument for Biblical Inspiration. Grand Rapids: Zondervan, 1980.

JURUÁ, P. A Manifestação do Espírito para a Caridade. São Caetano do Sul: Fundação Biblioteca Nacional, 2013.

KASS, L. R. (ed.). Beyond therapy: biotechnology and the pursuit of happiness. New York: Harper Collins, 2003.

KEIL, K. F.; DELITZSCH. F. Biblical Commentary on the Old Testament. Auckland: Titus Books, 2014.

KURZWEIL, R. The Singularity is Near: when humans transcend biology. London: Penguin Books, 2005.

LEVINAS, E. Otherwise than being or beyond essence. Netherlands: Springer, 2010.

LEVINAS, E. Totalidade e Infinito. Lisboa: Ediçóes 70, 1988.

LEWIS, C. S. A Abolição do Homem. In: LEWIS, C. S. A Abolição do Homem. Rio de Janeiro: Thomas Nelson Brasil, 2017. pp. 55-77.

LIMA, V. B. M. O conceito de amor em Emmanuel Lévinas. 2007. $151 \mathrm{f}$. Dissertaçáo (Mestrado em Filosofia) - Pontifícia Universidade Católica de Sáo Paulo, São Paulo, 2007.

MALDONADO-TORRES, N. Sobre la colonialidad del ser: contribuciones al desarrollo de un concepto. In: CASTRO-GÓMEZ, S; GROSFOGUEL, R. (Eds.). El giro decolonial. Reflexiones para una diversidad epistémica más allá del capitalismo global. Bogotá: Iesco-Pensar-Siglo del Hombre Editores, 2007. pp. 127-167.

MARCUSE, H. One-dimensional man: studies in the ideology of advanced industrial society. 2nd ed. Boston: Beacon Press, 1991. 
MARTINS, J. S. A existência intersubjetiva em Martin Buber. Argumentos, Fortaleza, ano 2, n. 4, pp. 28-37, 2010.

MORE, M. Transhumanism: toward a futurist philosophy. Extropy, 1990.

MORE, M.; VITA-MORE, N. The Transhumanist Reader. New Jersey: WileyBlackwell, 2013.

MORRIS, L. The Gospel according to John. Ed; rev; NICNT. Grand Rapids: Eerdmans, 1995.

MURDOCH, I. A soberania do Bem. São Paulo: UNESP, 2013.

NOZICK, R. N. Anarchy, State, and Utopia. Nova York: Basic Books, 1974.

OTTO, R. O sagrado: os aspectos irracionais na noção do divino e sua relação com o irracional. São Leopoldo: Sinodal/ Petrópolis: Vozes, 2007.

PEARCE, D. O Projeto Abolicionista (palestra). Happiness Conference. Oxford, 2007.

PEARCE, D. The hedonistic imperative, 1995. Disponível em: https://www. hedweb.com/hedethic/hedonist.htm. Acesso em: 20 nov. 2020.

RIEFF, P. The Triumph of the Therapeutic: uses of faith after Freud. New York: Harper \& Row, 1966.

ROHDEN, V. Racionalidade proposicional do eu e da mística. In: DALL'AGNOL, D. (org.). Verdade e respeito: a filosofia de Ernst Tugendhat. Florianópolis:

EdUFSC, 2007. pp. 357-376.

SANDEL, M. J. Contra a Perfeição: ética na era da engenharia genética. Rio de Janeiro: Civilização Brasileira, 2013. Versão eletrônica.

SPENCER, H. Social Statics. London, 1892.

STEINHART, E. C. Your Digital Afterlives: computation theories of life after death. New Jersey: Palgrave, 2014.

TUGENDHAT, E. Anthropologie statt Metaphysik. München: Verlag C. H. Beck, 2007.

TUGENDHAT, E. Antropologia como filosofia primeira. In: OLIVEIRA, Nythamar de; SOUZA, D. G. (org.). Hermenêutica e filosofia primeira: Festschrift para E. Stein. Ijuí: Unijuí, 2006. pp. 77-94.

TUGENDHAT, E. As raízes antropológicas da religião e da mística. In: ROHDEN, V. (org.). Não somos de arame rígido: Conferências apresentadas no Brasil em 2001. Canoas: Editora da Ulbra, 2002. pp. 93-111.

TUGENDHAT, E. Egocentricidade e Mística: um estudo antropológico. São Paulo: Martins Fontes, 2013. 
TUGENDHAT, E. Sobre mística. Diálogo Científico, Tübingen, v. 14, n.1-2, p. $121,2005$.

VIANNA, L.; BORGES, L. A. G. A filosofia transumanista subjacente aos aprimoramentos neurocognitivos e o risco de fragmentação do bem comum.

Ethic@: Revista Internacional de Filosofia da Moral, v. 20, n. 1, pp. 122-149, abr. 2021.

VILAÇA, M. M.; DIAS, M. C. M. Transhumanismo e o futuro (pós-)humano. Physis, Rio de Janeiro, v. 24, n. 2, 2014, pp. 341-362.

VILAÇA, M. M.; PALMA, A. Biological limits, biotechnoscience and transhumanism: a revolution in Public Health? Interface, v.16, n. 43, out./dez. 2012, pp. 1025-1038.

VON ZUBEN, N. A. Martin Buber: diálogo e cumplicidade. Bauru, SP: Edusc, 2003

VON ZUBEN, N. A. Tu Eterno e religiosidade no pensamento de Martin Buber. Horizonte, Belo Horizonte, v. 13, n. 38, pp. 941-968, abr./jun. 2015

VON ZUBEN, N. Introdução. In: BUBER, M. Eu e Tu. São Paulo: Moraes, 1979.

YOUNG, S. Designer evolution: a transhumanist manifesto. New York: Prometheus Books, 2009. Versão eletrônica.

Editor responsável: Eduardo R. Cruz

Enviado em: 26/11/2020

Aprovado em: 29/11/2021 